\title{
Effect of humidity and thermal aging on the absorption characteristics in polymer film
}

\author{
M M HOSSAIN \\ Department of Applied Physics and Electronics, Rajshahi University, Rajshahi, Bangladesh \\ MS received 16 April 1991; revised 25 November 1991 \\ Abstract. The absorption characteristics of polyimides and polyimide fluorocarhon polymer \\ Iilms were studied at different weathering conditions and after thermal aging. The absorption \\ current increased while the resorption current showed greater time dependence in the presence \\ of humidity. The magnitudes of the residual voltage decreased with increase of humidity and \\ temperature, but increased after thermal aging. The absorption and resorption current also \\ did not satisfy the traditional Curie-Von Schweidler law after weathering und aging.
}

Keywords. Absorption/resorption current; residual voltage; weathering; thermal aging; oxjdation; Curie-Von Schweidler law.

\section{Introduction}

Polymers are widely used in industry because of their mechanical and insulating properties. For practical applications in condenser, electro-acoustic transducer, cable and electret technology, a study of the effect of humidity and variation in ambient temperature on the absorption characteristics of polymer films is desirable. From a mechanical point of view, the absorbed water sometimes has a desirable plasticizing effect. Water vapours present in atmosphere may effect charge acceptance of a polymer film as wcll as the surface potential decay rate, depending upon (i) relative humidity, (ii) nature of the polymeric surface. (iii) time of exposure to humid surroundings, (iv) surface area of the film and (v) room temperature (Pillai et al 1980).

The effect of humidity under electric stress on the polymer produces force which is assumed to be caused by electric field gradient, diclcetric inhomogeneities, interfacial effects (e.g. water polymer interface) and coulombic forces on $\mathrm{H}^{+}, \mathrm{OH}^{-}$and $\mathrm{H}_{3} \mathrm{O}^{+}$ions. It may also happen that under electric field and in the presence of humidity, the temperature and pressure can rise with subsequent increase in the conduction current of the polymer (Abdollal et al 1982).

The absorption characteristics of polymer material were earlier studied by measuring the absorption/resorption current and residual voltage (Hossain 1988).

The application of step voltage to dielectric causes a flow of current which decays with time before reaching a steady-state value. The time-dependent part of current under applied electric field is called absorption current. The resorption current obtained during discharge of the sample usually decaycd with time in the direction opposite to the absorption current. This was explained as the result of dipolar depolarization or redistribution of charge carriers due to interfacial polarization or space charge polarization (Das Gupta et al 1980).

Considerable high voltage sometimes appears on the inner conductor of a power transmission cable and condenser after opening a circuit which was previously electrically stressed and short-circuited for a short time. This voltage gives an electric shock when touched and is terned the residual voltage (Kalsumi et al 1982). 
The present paper reports the comparative study of the effect of different weathering conditions and thermal aging on the absorption characteristics of polyimide (PM) and polyimide-1luorocarbon(PMP-2) polymer film.

\section{Experimental}

Commercial-gxade polyimide (Ysiovia 1972) and polyimide fluorocarbon film [10 $\mu \mathrm{m}$. fluorocarbon $-30 \mu \mathrm{m}$ polyimide $-10 \mu \mathrm{m}$ fluorocarbon sandwich film conmercially known as PMP-2 (Ysiovia 1983)] of thickness 40 and $50 \mu \mathrm{m}$ respectively were used. After washing with alcohol, the aluminium electrodes ( $28 \mathrm{~mm}$ diameter) were deposited on both surfaces of the film by vacuum evaporation. The sample was then mounted in a measuring cell and the absorption/resorption currents and the residual voltage at different conditions were measured using a electrometer, an $\mathrm{X}-\mathrm{Y}$ recorder provided with a time base, and a stabilized d.c. power supply.

The absorption/resorption currents were measured according to standard procedures viz applying a step voltage, measuring the absorption current decay for some polarizing time $t_{\mathrm{p}}$, short circuiting the sample and measuring the resorption current.

The measurement procedure of residual voltage was as follows: A voltage $V_{p}$ was applied to a sample for a time $t_{p}$ and the circuit shorted for a time $t_{s}$. After the circuit was opened, a residual voltage $V_{R}$ appeared on an electrode after time $t$.

Before deposition of the aluminium electrode, the samples were placed in the weather chamber at different conditions i.e. $40^{\circ} \mathrm{C}+65 \% \mathrm{RH}, 20^{\circ} \mathrm{C}+65 \% \mathrm{RH}$, $40^{\circ} \mathrm{C}+95 \% \mathrm{RH}$ and $20^{\circ} \mathrm{C}+95 \% \mathrm{RH}$ for 2 months and the experiment carried out at the same conditions. The accuracy of the weather chamber was of $\pm 1^{\circ} \mathrm{C}$ for temperature and $\pm 2 \%$ for relative humidity $(\mathrm{RH})$.

To observe the effect of thermal aging, the samples were placed in an oven at temperature $180^{\circ} \mathrm{C}$ for $5 \mathrm{~h}$ biefore deposition of electrodes and therealter the absorption/resorption currents were measured at the condition $40^{\circ} \mathrm{C}+65 \% \mathrm{RH}$.

\section{Results and discussion}

Variation of the absorption and resorption current with time for PM and PMP-2 polytmer film is shown in figures 1 and 2 respectively at various conditions. It is clear from the figures that weathering affected the absorption and resorption currents of both the PM and PMP-2 polymer films. Figures 1 and 2 also indicate that the conduction current (absorption current) increases with increase of humidity and temperature while the resorption current shows greater time dependence.

Abdollal et al (1982) showed that under electric stress and in the presence of humidity, the surface of the polymer was oxidized. During oxidation, carbonyl and hydroxy groups are normally produced. Once the polymer surface was oxidized it was hydrophillie and thus attracted more water present either in the surroundings or generated during oxidation. This accumulation of water caused electric stress enhancement as a result of increase of conduction current of the polymer.

The amount of water diffusing into polyrners also depended on the chemical structure and crystallinity, so the relaxation of trapped charge might have occurred as a result of moleeular upheaval. Increased rate of observed decay in the resorption current might have been due to the motion of injected charges which were liberated by penetration of water molecule. 


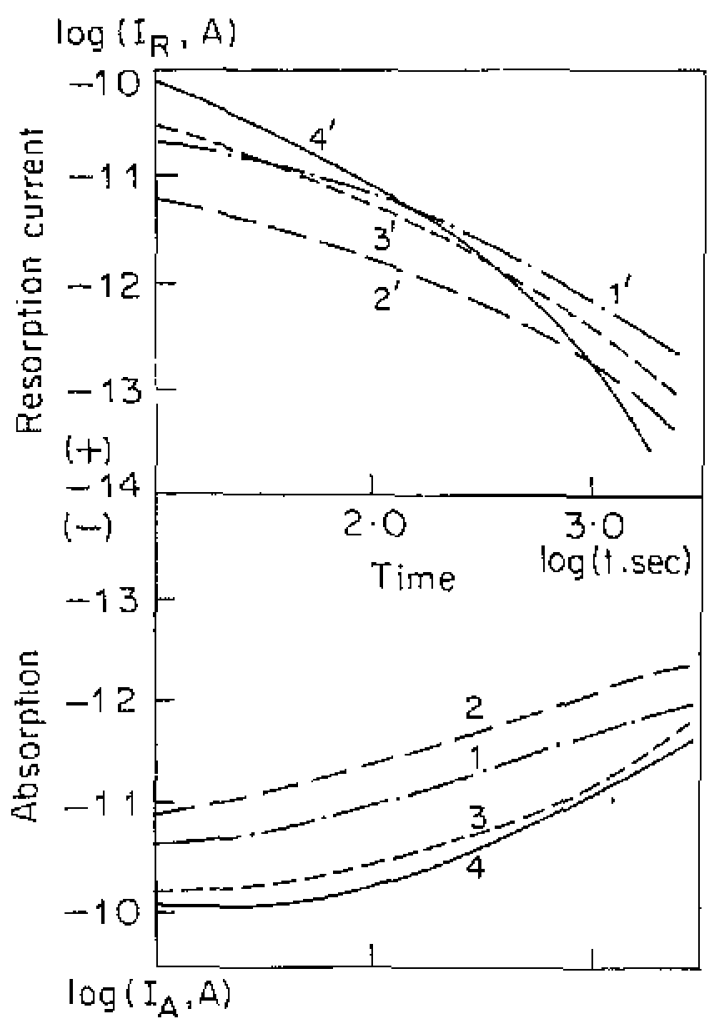

Figure 1. Time dependent absorption/resorption currents of PM polymer film. Normal fil In ( $\left(11^{\prime}\right)$, after thermal aging $\left(2 \cdot 2^{\prime}\right)$, after weathering at the conditions $20^{\prime \prime} \mathrm{C}+95^{\circ} \% \mathrm{RH}\left(3 \cdot 3^{\prime}\right)$ and $40^{\circ} \mathrm{C}+95 \% \mathrm{RH}(4 \cdot 4), E_{r}=32.5 \mathrm{kV} / \mathrm{cm}$.

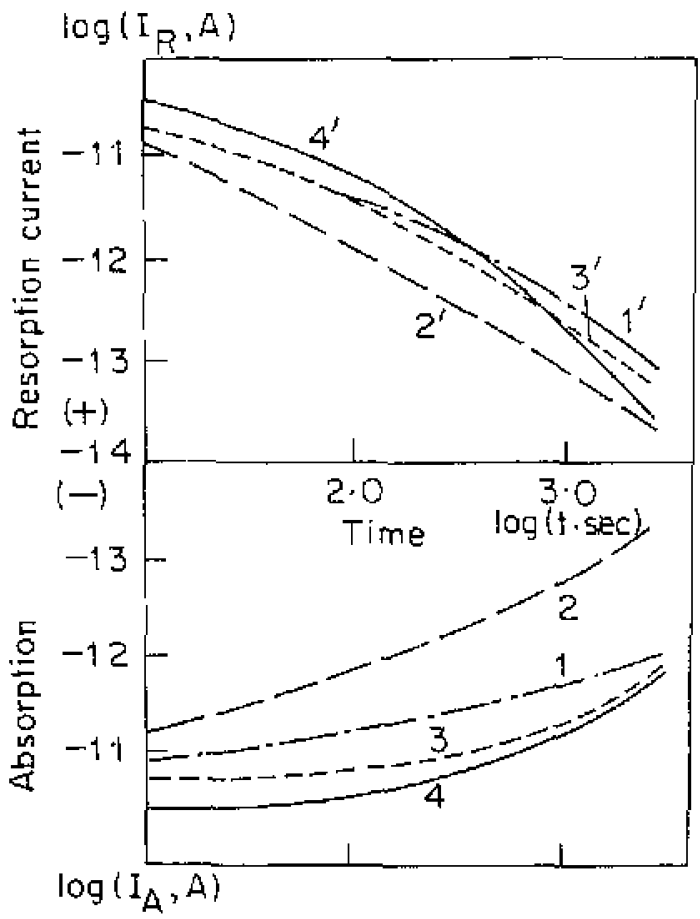

Figure 2. Time-dependent absorption/resorption currents of PMF-2 polymer film. Delails as in ligure $\mathrm{L}$. 
The absorption and resorption currents for $\mathrm{PM}$ and $\mathrm{PMP}-2$ polymer films after thermal aging are also shown in figures 1 and 2. Magnitudes of both absorption and resorption currents were found to decrease by thermal aging. The decrease in absorption/tesorption curtent was then related to the dipole process and probably to a change in ionic or dipole concentration, which was produced during thermal aging. It was also observed that the absorption/resorption current for $\mathrm{PMF}-2$ polymer film showed greater time dependence after aging. During thermal aging at $180^{\circ} \mathrm{C}$, the upper thin fluorocarbon layer $(10 \mu \mathrm{m})$ started to soften and became noncontinuous (Hossain 1989). This may well be related to increase in the trap density between the polyimide and fusorocarbon layers and results in more time being taken in the charge storage and relaxation process of PMF-2 polymer film.

It is also seen from figures 1 and 2 that the logarithmic plots of absorption and resorption currents are not linear, i.e. the observed time dependence of the current transients does not satisfy the Curie Von Schweidler law (Van der Schueren and Linkens 1976)

$$
I(t)=A(T) t^{-\pi}
$$

where $J$ is the absorption/resorption current, $t$ the time and $A(T)$ the temperature dependence factor. The absorption/resorption current in the presence of humidity and after thermal aging for both the above mentioned films may also be written in terms of the sum of exponents which are functions of time (Hossain 1989, 1991) i.e.

$$
I=\sum_{i=1}^{n} I_{A, \mathrm{R}}^{0} \exp \left(-t / t_{\mathrm{A}, \mathrm{R}}\right)
$$

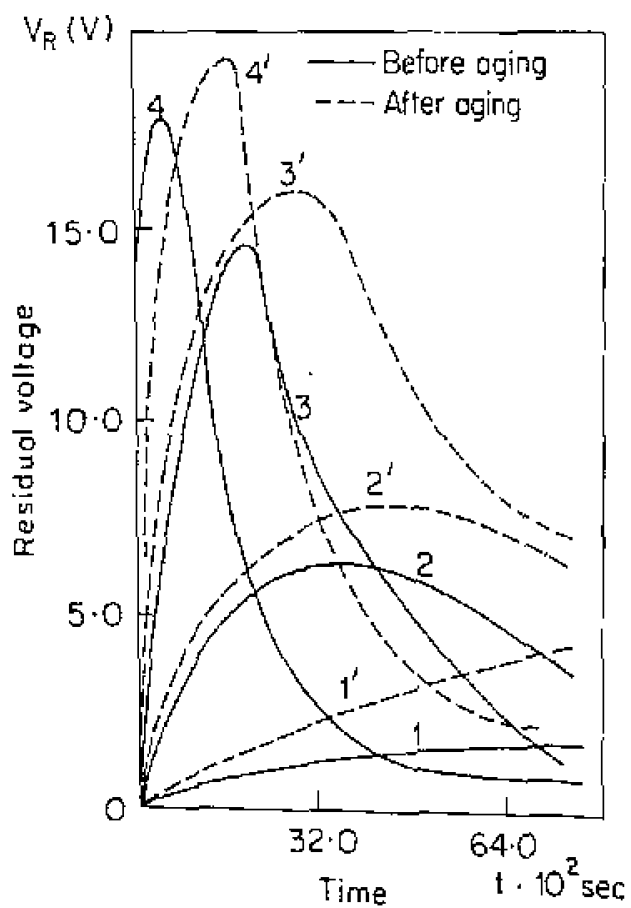

Figure 3. Time-dependent residual voltage for $\mathrm{PM}$ polymer film. Temperature of polatization $80^{\circ} \mathrm{C}\left(\mathrm{I}^{\prime} 1^{\prime} \mathrm{h}, 120^{\circ} \mathrm{C}\left(2 \cdot 2^{\prime}\right), 160^{\circ} \mathrm{C}\left(3^{\prime \prime}\right)\right.$ and $180^{\circ} \mathrm{C}\left(4^{\prime} \cdot 4^{\prime}\right), \mathrm{t}_{\mathrm{p}}=2 \mathrm{~h}, t_{\mathrm{s}}=5 \mathrm{~s}$ 


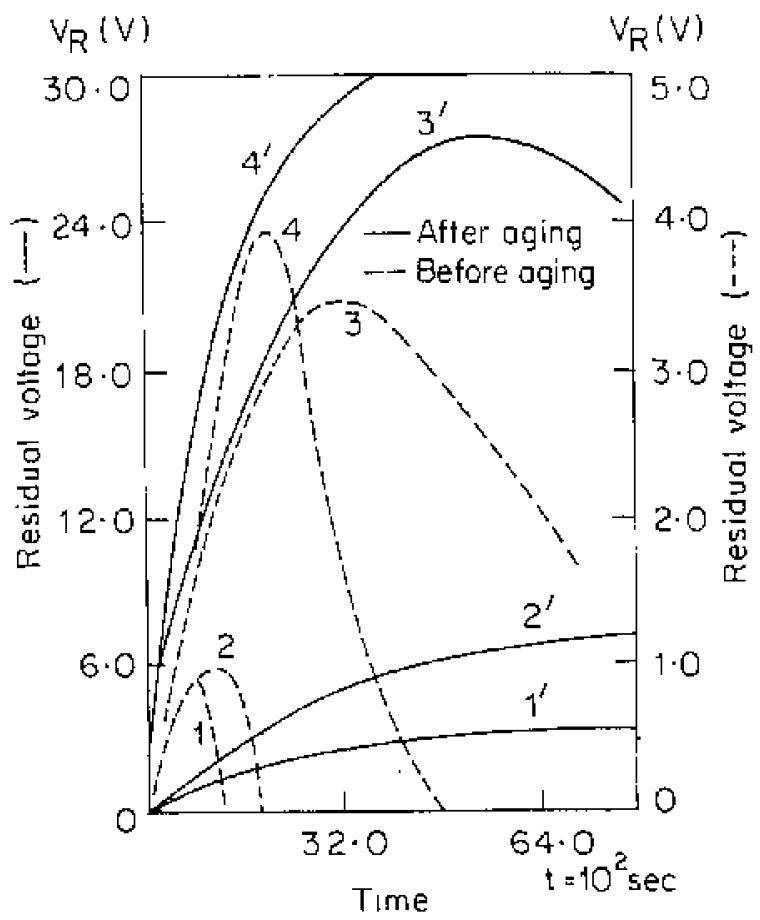

Figure 4. Time-dependent residual voltage for PMF-2 polymer film. Details as in figure 3.

where $\tau_{\mathrm{A}, \mathrm{R}}$ is the relaxation time for absorption and resorption current respectively. Variation of the residual voltages with time for PM and PMF-2 polymer films at various polarization temperature before and after the thermal aging is shown in figures 3 and 4 . The residual voitage increases with increase of temperature of polarization for both cases. The magnitudes of residual voltage increase after thermal aging and this may be telated to a decrease in the conductivity of the sample. The origin of residual voltage can then bc explaincd qualitatively from experimental results as follows. Under a constant voltage and rise of temperature, the carriers pre-existing in the film or injected from the electrode, migrate within the film and establish a space charge distribution. During short-circuiting, the charge redistributes in the sample and some of the charges will be swept out of the electrode. After the circuit is opened, charge distribution is rearranged by migration of carriers in the film because of the space charge field, resulting in the appearance of residual voltage which is due to charge imbalance on the electrode and the sample (Hossain 1990).

Time-dependent residual voltage at different polarization conditions for PM and PMF-2 polymer film is shown in figures 5 and 6 respectively. It is clear that magnitudes of the residual voltage decrease with increase of temperature and humidity. The possible reason for reduction in residual potential of polymer would be the reaction with oxyger in the presence of humidity. On the surface, oxidation proceeds with a time constant longer than that required for formation of an equilibrium water film which might lead to formation of a more water-susceptible surface. It might also lead to conduction in layers below the surface.

The decrease in time for obtaining a residual voltage peak with increase of 


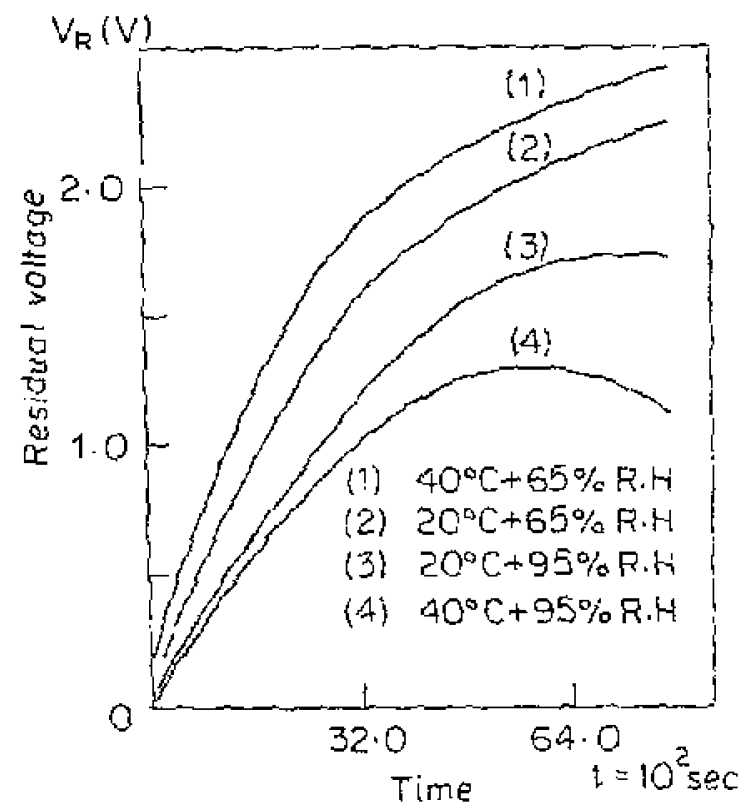

Figare 5 . time dependent residual voliage for PM polymer lim at siffercst weathering cunditions. $T_{3}=80^{\circ} \mathrm{C}, t_{t}=2 \mathrm{~h}, \mathrm{r}_{2}=5 \mathrm{~s}$.

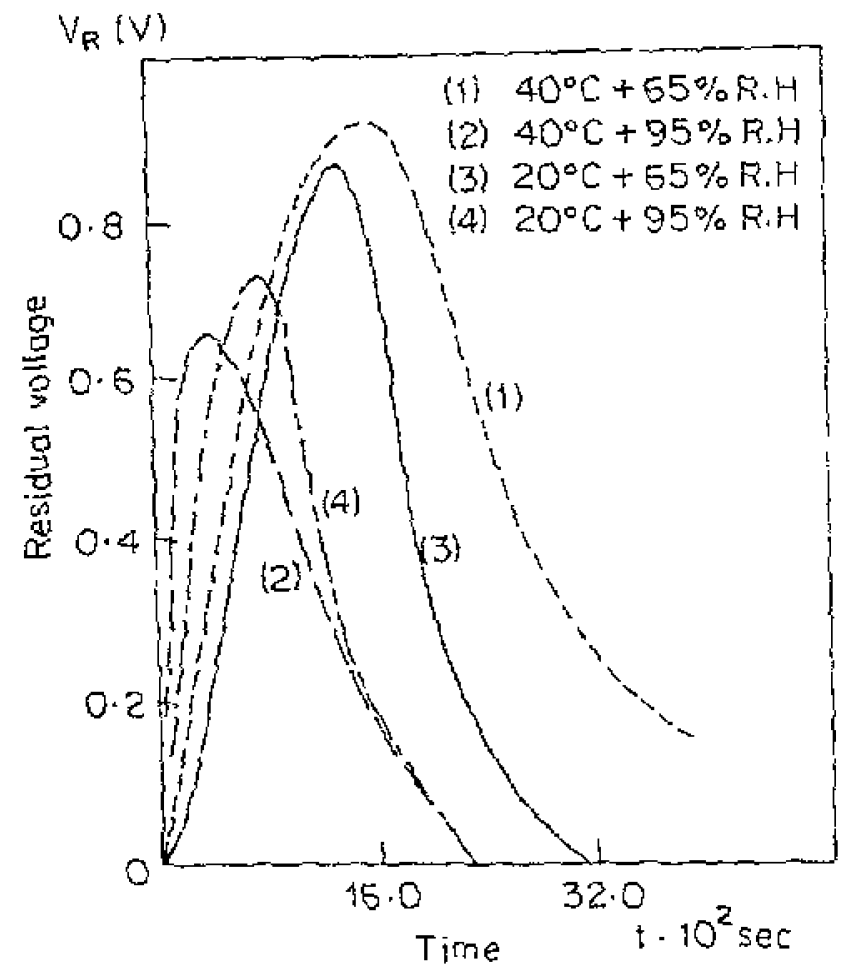

Figure 6. Time-dependent residual valtage for PMF-2 polymer thim at different weathering conditions. Details as in ligure 5 . 
temperature and humidity (figures 5 and 6 ) may be related to increase in conductivity due to the diffusion of water into the sample.

Thus it is expected that absorption characteristics should be very much affected by changes in humidity.

\section{Conclusion}

The absorption current increases due to oxjdalion of polymer surface in the presence of humidity while the resorption current shows more time dependence. The logarithmic plots of absorption and resorption currents do not satisfy the Curie-Von Schweidler law and are the time-dependent summation of exponents like sample PM and PMF-2 polymer films beiore weathering and aging. The magnitudes of residual voltage decrease with inctcase of humidity and lemperature while it increases after thermal aging.

\section{References}

A.bdolla] K, Orton H E, Reynolds M W. Robert B D, Kenncdy R and Clayman B P 1982 Anmual Rept. Conf. Elet. Insul, and Dielectric Phenomena, Amherst, Mass 17-21 Oct. 1982. New York, pp. 604

Das-Gupta D K, Doughty K and Brocklay R S 1980 J. Fhys. D13 2101

Hossain M M 1988 J wian J. Phys. A62 944

Hossain M M 1989 Indiun J. Phys A63793

Hossain M M 1990 Pramana-J. Phys. 34565

Hossein $M$ M 1991 indion J. Plys. A65 236

Kalsumi Y, Jun K, Murnoo Y, Ken-lchi N, Yoshio I and Nobuharu K 1982 Jm J. Appl. Phys, 211333

Pillai P K C, Gupld A K and Malti 1980 IAS (IEEE Ind. Appl. Sor.) 15th Annu. Meting, Cincinnati, New York, pp. 1159

Yan der Schuten J and Linkens A $1976 \mathrm{~J}$. Appl. Phys. 494195

Yslovia T 6-05-1491-1972 USSR

Yslovia T 6 19-226-198? USSR 